\title{
Chronic Effects of Brahmi (Bacopa monnieri) on Human Memory
}

\author{
Steven Roodenrys, Ph.D., Dianne Booth, M.Sc., Sonia Bulzomi, G.Dip.App.Psyc., Andrew Phipps, \\ G.Dip.App.Psyc., Caroline Micallef, G.Dip.App.Psyc., and Jaclyn Smoker, G.Dip.App.Psyc.
}

\begin{abstract}
A study is reported on the effects of Brahmi (Bacopa monniera) on human memory. Seventy-six adults aged between 40 and 65 years took part in a double-blind randomized, placebo control study in which various memory functions were tested and levels of anxiety measured. There were three testing sessions: one prior to the trial, one after three months on the trial, and one six weeks after the completion of the trial. The results show a significant effect of the Brahmi on a test for the retention of new information. Follow-up tests showed that the rate of
\end{abstract}

learning was unaffected, suggesting that Brahmi decreases the rate of forgetting of newly acquired information. Tasks assessing attention, verbal and visual short-term memory and the retrieval of pre-experimental knowledge were unaffected. Questionnaire measures of everyday memory function and anxiety levels were also unaffected.

[Neuropsychopharmacology 27:279-281, 2002] (C) 2002 American College of Neuropsychopharmacology. Published by Elsevier Science Inc.
KEY WORDS: Psychopharmacology; Memory; Herbal medicine; Applied psychology; Psychology; Short-term memory

Brahmi (Bacopa monniera Linn.) is a herb which occurs naturally in India and has a long history of use in the Ayurvedic medicine tradition in the treatment of a number of disorders, particularly those involving anxiety, intellect and poor memory (Singh and Dhawan 1997). It is currently being marketed in Western countries as a memory enhancing agent. Studies have shown that the herb contains many active constituents, including a number of alkaloids and saponins, however, the

From the Department of Psychology, University of Wollongong, Woolongong, Australia.

Address correspondence to: Dr. S. Roodenrys, Department of Psychology, University of Wollongong, Northfields Ave, Wollongong, 2522, Australia. Tel.: (+61) 242214 072, fax: (+61) 242214 163, E-mail: steven_roodenrys@uow.edu.au

Received March 29, 2001; revised November 6, 2001; accepted November 29, 2001.

Online publication: $11 / 29 / 01$ at www.acnp.org/citations/ Npp112901214. major constituents are the steroidal saponins, Bacosides $\mathrm{A}$ and $\mathrm{B}$.

There are no published scientific studies of the effects of brahmi on memory in humans; however there are some behavioral studies with rats. These studies have shown that it improves the rate of learning in a brightness discrimination task and a conditioned avoidance task, that it improves retention, as demonstrated by savings in relearning, and that it attenuates amnesia induced by immobilization, electroconvulsive shock and scopolamine (Singh and Dhawan 1997). This latter finding involved administration of the extracted bacosides, A and B, and suggests that they influence cholinergic systems. Recently, however, it has been reported that brahmi has an antioxidant effect in the rat frontal cortex, striatum and hippocampus (Bhattacharya et al. 2000).

The aim of the current study was to examine the effects of an extract of Bacopa monniera on cognitive function. Based on the behavioral studies with rats, described above, it is expected that it will improve performance on tasks tapping long-term memory. 


\section{METHODS}

Eighty-four healthy volunteers who were not taking any medication or other herbal preparation, and reported no head injuries, commenced the study. Eight participants withdrew after the first testing session, four from each group. Only one of these was due to an adverse (gastrointestinal) reaction to the brahmi capsules. Two of the participants in the placebo group withdrew when they developed a medical condition. At the second testing session and a mid-trial telephone call participants were asked about their memory function and given an opportunity to make other comments. On these occasions no other participants reported adverse reactions. Seventy-six participants ( 28 males and $48 \mathrm{fe}-$ males) between the ages of 40 and 65 years (mean 49 , S.D. 7), completed the study.

\section{Design}

The study utilized a double-blind, randomized placebo controlled independent group design with two groups; a Bacopa monniera (Keenmind extract) group $(n=37)$ and a placebo group $(n=39)$.

\section{Procedure}

Participants were tested on three separate occasions for approximately one hour. In the first session pre-trial testing was completed (baseline) and the participants were given three months supply of capsules at the dosage recommended by the manufacturers $(300 \mathrm{mg}$ for persons under $90 \mathrm{~kg}$, and $450 \mathrm{mg}$ for persons over 90 $\mathrm{kg}$, equivalent to $6 \mathrm{~g}$ and $9 \mathrm{~g}$ dried rhizome, respectively). Participants were contacted by telephone approximately six to eight weeks into the trial period to encourage compliance. A second testing session was conducted approximately three months later (3-month test), at which participants were instructed not to take any remaining capsules. A post-trial testing session occurred approximately six weeks after the end of trial session.

At each testing session a battery of tasks was administered to assess attention, a range of memory abilities, and psychological state. The order of administration of the tasks was the same for each session, and was as follows: A questionnaire about everyday memory performance (adapted from Bennett-Levy and Powell 1980); Immediate recall of a short story; Digit span — forward and backward; A speeded coding task involving either directly copying each letter presented, writing the next letter in the alphabet or the previous letter (as described by Neubauer and Knorr 1998); Delayed recall of the short story read earlier; Three trials of learning six unrelated word pairs; A visual span task requiring tapping a sequence of blocks in correct order - forward and backward; A general knowledge test of 20 questions (selected from Nelson and Narens 1980); Delayed recall of the word pairs; The Depression, Anxiety and Stress Scale (Lovibond and Lovibond 1995).

Table 1. Means (and SD) for all tasks by group and testing session.

\begin{tabular}{|c|c|c|c|c|c|c|}
\hline \multirow[b]{2}{*}{ Task } & \multicolumn{3}{|c|}{ Brahmi Group } & \multicolumn{3}{|c|}{ Placebo Group } \\
\hline & Pre-trial & End of trial & Post-trial & Pre-trial & End of trial & Post-trial \\
\hline Memory questionnaire & $3.18(0.6)$ & $2.77(0.7)$ & $2.88(0.5)$ & $3.00(0.4)$ & $2.77(0.6)$ & $2.72(0.6)$ \\
\hline General knowledge & $10.97(3.1)$ & $10.64(2.7)$ & $11.84(3.5)$ & $10.43(3.2)$ & $10.36(3.0)$ & $11.49(2.9)$ \\
\hline \multicolumn{7}{|l|}{ Story recall } \\
\hline Immediate & $15.97(5.5)$ & $15.22(5.2)$ & $15.05(3.7)$ & $16.77(5.3)$ & $15.28(5.7)$ & $16.67(6.3)$ \\
\hline Delayed & $14.69(5.3)$ & $13.65(5.0)$ & $13.78(4.4)$ & $15.28(5.8)$ & $14.38(5.1)$ & $16.05(6.6)$ \\
\hline \multicolumn{7}{|l|}{ Word pairs } \\
\hline Trial 1 & $1.05(1.4)$ & $2.11(1.6)$ & $1.46(1.5)$ & $0.90(1.2)$ & $1.68(1.8)$ & $1.51(1.4)$ \\
\hline Trial 2 & $1.97(1.7)$ & $3.14(1.7)$ & $2.54(2.0)$ & $1.62(1.6)$ & $2.95(1.9)$ & $2.54(1.9)$ \\
\hline Trial 3 & $2.38(2.1)$ & $3.81(2.0)$ & $3.32(1.9)$ & $2.51(1.9)$ & $3.44(2.1)$ & $3.33(2.1)$ \\
\hline Delayed & $2.24(2.1)$ & $3.68(1.9)$ & $2.68(1.9)$ & $2.08(1.8)$ & $2.90(2.2)$ & $2.95(2.0)$ \\
\hline \multicolumn{7}{|l|}{ Digit span } \\
\hline forward & $6.05(1.2)$ & $5.97(1.2)$ & $6.28(1.3)$ & $6.27(1.3)$ & $6.58(1.4)$ & $6.55(1.2)$ \\
\hline backward & $4.07(1.2)$ & $4.04(1.3)$ & $4.24(1.1)$ & $4.23(1.3)$ & $4.45(1.2)$ & $4.56(1.4)$ \\
\hline \multicolumn{7}{|l|}{ Visual span } \\
\hline forward & $4.53(0.9)$ & $4.78(0.8)$ & $4.76(0.9)$ & $4.68(1.0)$ & $4.81(0.9)$ & $4.85(0.9)$ \\
\hline backward & $4.53(0.7)$ & $4.58(0.6)$ & $4.41(0.7)$ & $4.59(0.6)$ & $4.71(0.7)$ & $4.64(0.7)$ \\
\hline \multicolumn{7}{|l|}{ Coding } \\
\hline Copy & $44.08(7.6)$ & $47.19(7.8)$ & $46.32(8.3)$ & $42.62(8.7)$ & 44.64 (7.6) & $46.90(7.6)$ \\
\hline Next letter & $18.57(9.4)$ & $19.17(8.0)$ & $20.97(9.6)$ & $18.08(5.4)$ & $20.15(5.8)$ & $23.38(8.6)$ \\
\hline Prev. letter & $11.54(7.0)$ & $12.56(5.3)$ & 13.49 (6.4) & $10.77(4.1)$ & $10.97(3.7)$ & $12.21(4.2)$ \\
\hline DASS - D & $8.19(6.7)$ & $5.76(7.0)$ & $5.54(6.5)$ & $5.97(6.0)$ & $4.44(5.9)$ & 4.87 (5.9) \\
\hline A & $5.11(5.3)$ & $5.22(6.4)$ & $4.32(6.2)$ & $3.59(4.7)$ & $3.62(4.8)$ & $2.82(4.3)$ \\
\hline$S$ & $9.92(6.3)$ & $9.78(7.8)$ & $9.32(7.4)$ & $9.08(7.4)$ & $7.92(7.8)$ & $6.87(6.4)$ \\
\hline
\end{tabular}




\section{RESULTS}

The mean scores for each task are presented in Table 1 . Preliminary $t$-tests showed no differences between the two groups at baseline on any measures. The results from all tasks were analyzed by repeated measures Analysis of Variance (ANOVA) with two factors, Group (Brahmi and placebo), and Testing Session (baseline, 3-month, and post-trial) as a withinsubjects factor. The strongest test of the hypothesized effect of Brahmi is provided by a planned quadratic contrast across Testing Session interacted with the Group factor.

The only measure to show a significant effect was the delayed recall of word pairs task, $\mathrm{F}_{1,74}=4.932, p<.05$. Follow-up analyses using ANOVA showed significant reduction in performance between the last learning trial and the delayed recall test in all three testing sessions $\left(\mathrm{F}_{1,74}=6.035, p<.05, \mathrm{~F}_{1,74}=12.256, p<.01\right.$, and $\mathrm{F}_{1,74}=$ $18.830, p<.01$, repectively) however, only in the end of trial session did this effect differ significantly between groups, $\mathrm{F}_{1,74}=4.394, p<.05$. As can be seen in Table 1 , the group who received the Brahmi retained more word pairs over the delay than the placebo group.

\section{DISCUSSION}

The results show no significant effect of chronic administration of brahmi on measures of short-term memory, working memory, attention, or the retrieval of information from long-term memory acquired pre-experimentally. Further, there were no significant effects on subjective measures of psychological state (depression, anxiety and stress) or everyday memory function.

There was a significant effect on a task requiring the retention of new information: the recall of unrelated word pairs after a short delay. There were no significant differences associated with the rate of acquisition of the information, as evidenced by the lack of a significant difference between groups in the learning trials. Rather the effect appears to be a reduction in the amount of information lost from memory. The story recall task also required participants to learn some new material and recall it a short time later; however, it did not show the same significant effect. This may be be- cause there was very little forgetting of the material during the delay, or because story recall is a more reconstructive process than the recall of unrelated word pairs (Baddeley 1990).

The analyses were not adjusted for multiple measures, and it should be acknowledged that the results may reflect a Type I error. A further limitation is that no systematic attempt was made to document any adverse reactions to the capsules.

There is evidence of an antioxidant effect of Brahmi in the hippocampus (Bhattacharya et al. 2000). When combined with the finding of improved retention of information in this study, this suggests that the effect of the extract of Bacopa monniera may be mediated by antioxidant action within the hippocampus.

\section{ACKNOWLEDGMENTS}

We would like to thank Keenmind Pty Ltd for supplying the Brahmi and placebo for this study, all of our participants, and Pradeep Nathan and two anonymous reviewers for comments on drafts of this article.

\section{REFERENCES}

Baddeley A (1990): Human Memory: Theory and Practice. London, Erlbaum.

Bhattacharya SK, Bhattacharya A, Kumar A, Ghosal S (2000): Antioxidant activity of Bacopa monniera in rat frontal cortex, striatum and hippocampus. Phytother Res 14:174-179

Bennett-Levy J, Powell GE (1980): The subjective memory questionnaire (SMQ). An investigation into the self-reporting of 'real-life' memory skills. Br J Soc Clin Psychol 19:177-188

Lovibond SH, Lovibond PF (1995): Manual of the DASS (2 $2^{\text {nd }}$ ed). Sydney, Sydney Psychology Foundation

Nelson TO, Narens L (1980): Norms of 300 general information questions: Accuracy of recall, latency of recall and feeling of knowing ratings. J Verbal Learn Verbal Behav 19:333-368

Neubauer AC, Knorr E (1998): Three paper-and-pencil tests for speed of information processing: Psychometric properties and correlations with intelligence. Intelligence 26:1-25

Singh HK, Dhawan BN (1997): Neuropsychopharmacological effects of the Ayurvedic nootropic Bacopa Monniera Linn. (Brahmi). Indian J Pharmacol 29:359-365 